\title{
A Prisoner with an Unusual Karyotype (46,XY,Dq-)
}

\section{J. KAHN* and FREDA REED $\dagger$}

We wish to report the case of a physically normal offender whose karyotype shows an unusually short D chromosome.

\section{Case Report}

The patient is an only child, his parents divorced when he was 5 and he remained with his mother; shortly afterwards he became beyond parental control and was placed in a Children's Home until the age of 12; from there he went to a school for maladjusted children where he stayed 2 years, he is reported to have frequently run away from there or stayed out late. At 14 he went to an approved school for a 'breaking and entering' offence and thereafter he progressed from Borstal to prison. All offences have been acquisitive or motoring offences.

His behaviour is impulsive and unstable; he has made suicide gestures, absconded from penal establishments, and discharged himself from the Psychiatric Hospital where he was receiving treatment after leaving Borstal.

$\mathrm{He}$ is of average intelligence and has a pleasant manner and is by now thoroughly institutionalized, he settles and works well wherever he is currently confined but shortly before he is due for discharge his anxieties culminate in some foolish act which may prolong his confinement; after one release he was rearrested within 10 days, on another occasion he escaped within weeks of his release date and immediately committed further offences.

At the age of 21 his height is $6 \mathrm{ft} 2 \mathrm{in}$, weight $168 \mathrm{lb}$. No physical abnormalities are noted.

Cytology. F. R. referred the patient for investigation of his chromosomes because it was thought he might have an XYY sex-chromosome complement.

Twenty cells of a leucocyte culture were analysed. Every cell contained one short $\mathrm{D}$ chromosome in an otherwise normal male karyotype; $46, \mathrm{XY}, \mathrm{Dq}-$ (Fig. 1a, b, c, and d). The patient absconded before further investigations could be carried out.

The mother's karyotype was normal. The father now living in Australia is not available for investigation.

\footnotetext{
Received 1 October 1970.

* Institute of Psychiatry, Department of Psychiatry, De Crespigny Park, London SE 5.

+ Prison medical officer.
}

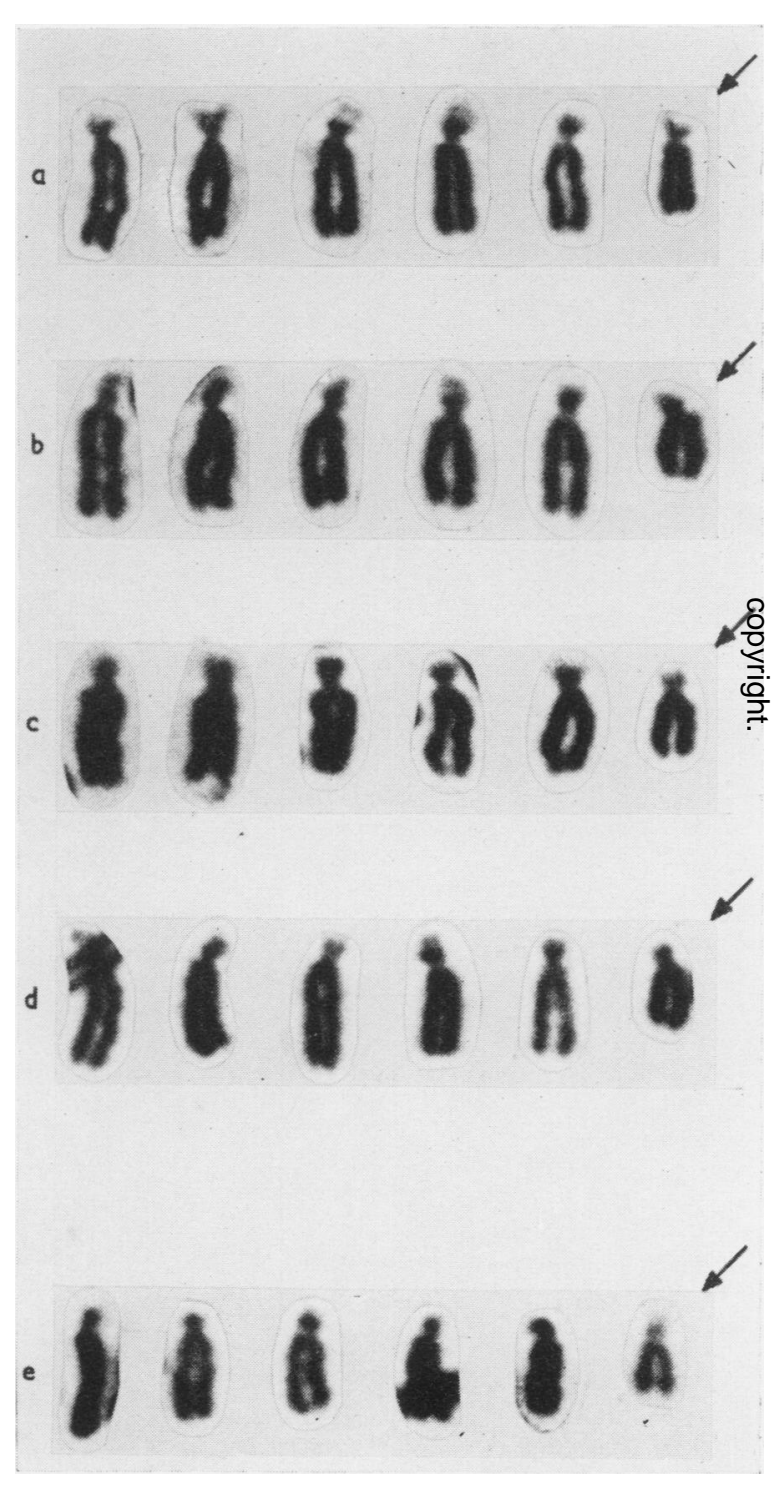

FIG. 1. Partial karyotypes showing chromosomes 13-15 (arrows indicate chromosomes with deletion); $a-d=$ patient, for e see discussion. 


\section{Discussion}

Wilson et al (1969) summarized 4 cases of a partially deleted $\mathrm{D}$ chromosome associated with retinoblastoma and varying degrees of retarded mental as well as physical development. Because of the lack of physical abnormalities in our patient, it is more difficult to account for the morphological abnormality of the D chromosome. Some of the more likely explanations are: (1) the loss of a segment which carries few genes; (2) a balanced translocation between the $\mathrm{D}$ and a larger chromosome, not sufficient to render the larger chromosome distinguishable from its homologue; (3) undetected mosaicism; or (4) differential coiling giving rise to a marker chromosome.

In a survey of a Borstal population Kahn et al (1969) described a case of a boy with mosaicism for a similar D chromosome 46,XY/46,XY,Dq - (Fig. 1e). In this case 3 out of 30 cells of a blood culture contained the abnormality. It is hoped that future studies will show whether or not this type of abnormality is more frequent in delinquent populations.

\section{Summary}

The case is described of a physically normal offender whose karyotype shows an unusually short D chromosome.

\section{REFERENCES}

Kahn, J., Carter, W. I., Dernley, N., and Slater, E. T. O. (1969). Chromosome Studies in remand home and prison populations. In Cropwood Round-table Conference on Criminological Implications of Chromosome Abnormalities, ed. by D. J. West, pp. 44-48. Institute of Criminology, Cambridge.

Wilson, Miriam G., Melnyk, J. and Towner, J. W. (1969). Retinoblastoma and deletion $\mathrm{D}(14)$ syndrome. Fournal of Medical Genetics, 6, 322-327. 